Volume 8, No.1.1, 2019

International Journal of Advanced Trends in Computer Science and Engineering

Available Online at http://www.warse.org/IJATCSE/static/pdf/file/ijatcse5581.12019.pdf

https://doi.org/10.30534/ijatcse/2019/5581.12019

\title{
Mobile Commerce in Europe - Comparative Study
}

\author{
Aleksandra PTAK \\ Faculty of Management, Czestochowa University of Technology, Czestochowa, Poland \\ olaptak@zim.pcz.pl
}

\begin{abstract}
:
Mobility is today one of the strongest trends in the business and increasingly important sales channel in Europe. According to the data collected by Twenga Solutions in 2015, European countries have the highest mobile penetration rate in the world - in Central and Eastern Europe it is 151 percent, while the rate in Western Europe is 129 percent. The paper presents general information on m-commerce, the situation of mobile commerce in the European countries and threats to which mobile consumers are exposed. The paper also contains results of a survey conducted on a group of Polish e-consumers on their mobile purchases experience.
\end{abstract}

Key words: E-commerce; M-commerce; Mobile Sale; E-store; Europe

\section{INTRODUCTION}

E-commerce market, especially the part concerning mobile commerce, is an extremely dynamic area. Many shops have adapted their tools for mobile purchases for a coherent and integrated management of all sales and communication channels [1]. Mobile marketing allows to increase the effectiveness of activities related to customers relationships management thanks to enhancing the quality of customer service; organization of work thanks to improved communication between employees, implementation of current activities in an automated way, without the personal involvement of employees [2]. When deploying a mobile version of the e-store one should take into account: the utility, a small size of the application, speed, reliability, introduction of all necessary functions. By implementing mobile solutions, shops increase their availability, and hence its sales and popularity [3]. This is dictated by the desire to secure access to the store offer practically in all conditions, such as: during coffee break, on the way to work etc. The most popular are sites optimized for smartphones, which according to statistics, have about 79 percent of e- shops, declaring the use of mobile solutions.

Thanks to mobile devices sellers can provide personalized content and offers for specific customers. Taking into account the speed of the mobile channel, the mentioned above can be a major factor in inducing users of smartphones and tablets to buy. Companies wishing to provide services or sell goods in the mobile channel have to introduce solutions which are more attractive than previously known (faster and more convenient). Mobile version of Internet business slowly becomes a necessity determining the competitiveness on the market, and implementing multi-channel sales strategy [4] including m-commerce is becoming strong element supporting e-commerce.

\section{RISK INHERENT TO THE MOBILE SALE}

The constant development of the mobile industry, however, entails many risks. The user of the mobile device must be aware that it is exposed to hackers, criminal organizations etc [5,6].

- Attacks on mobile payment services. With mobile payment services the potential danger increases. The danger is associated with the problem of the lack of verification (by the bank) of the data entered by the user to the mobile payment services (number of debit or credit card). At risk are not only the most popular payment services but also payment applications peer-to-peer.

- System attacks through the gaps in mobile browsers. Device hacking "by" browser, turns out to be one of the most effective ways to take control over the device. The gap in the Android browsers code, called Stagefright, allowed hackers to take control over the smartphone after opening of the MMS.

- Terrorism. With applications based on the end-to-end encryption, criminal organizations can communicate without any restrictions or controls from third parties.

- Remote devices eavesdropping. Devices with running android have pre-installed applications from producers which are usually not checked by the Google security team. These apps can expose the device for a number of dangers such as, for example, remote interception of the device.

- DDoS attacks. Attacks on a computer system or network service in order to prevent action by taking over all the available resources. It is carried out from multiple computers at the same time

- The Internet of things. Big hopes for the future are related with intelligent everyday appliances, connected to the Internet (cars, childrens' toys, medical devices). Programs using software vulnerabilities (exploits) can be very dangerous not only for the money, data and information security but also health or even life.

\section{M-COMMERCE IN EUROPE- POSITION AND DIFFERENCES}

M-commerce is playing an increasingly important role among both consumers and online retailers. Each year analysts of Twenga Solutions carry out the research to determine the latest trends of European mobile consumers. In 2015, once again they examined the data traffic on smartphones, tablets and desktops from the stores of seven selected European countries [7]. 
The study involved over 4,000 stores and the surveyed countries were:

- United Kingdom,

- France,

- Germany,

- Spain,

- Italy,

- The Netherlands,

- Poland.

Figure 1 presents a list of selected European countries, including their share in mobile shopping

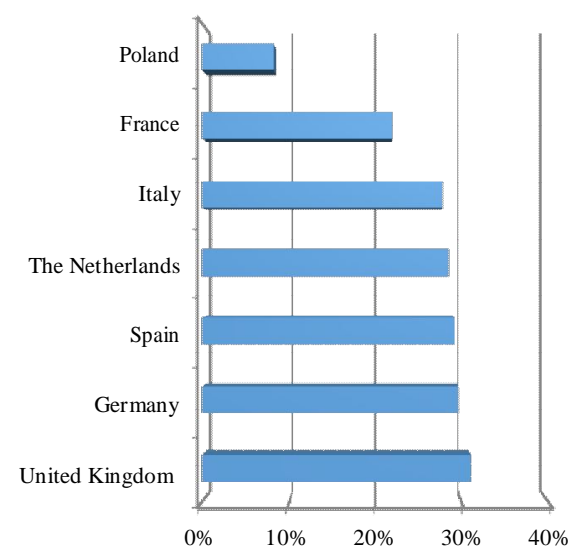

Figure 1: Mobile traffic share

According to research conducted in 2015 among European countries included in the analysis, the most numerous group of mobile buyers comes from the United Kingdom, while the least numerous group comes from of Poland.

Figure 2 presents the most popular devices, through which Europeans were purchasing by mobile in 2015 , by country.

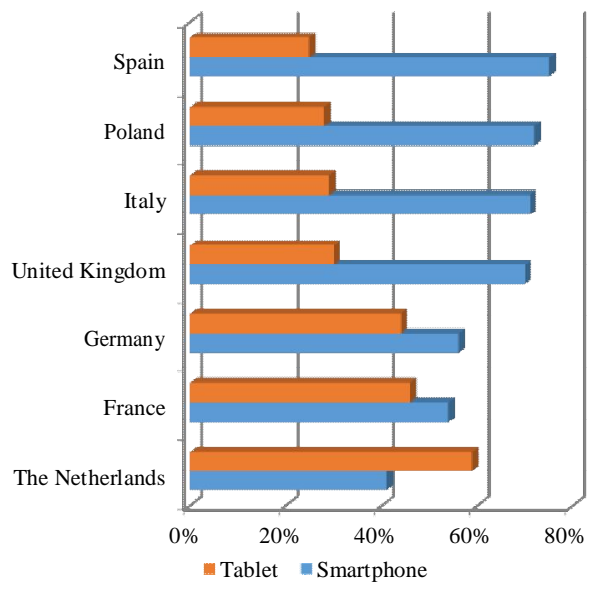

Figure 2: The most popular mobile device
As shown in fig. 2, the most popular mobile device is smartphone. The country, where the most of consumers do shopping by mobile with the use of smartphones is Spain, with a score of 75 percent. Second place is occupied by Poland, where smartphones choose 72 percent of mobile buyers. The third place is occupied by Italy with a score of 71 percent buyers who prefer purchasing with the use of smartphones. The country where consumers choose mobile shopping with the use of tablets (59 percent) rather than smartphones (41 percent) is the Netherlands.

An interesting part of the research are the product categories which are the most popular in chosen European countries. It turned out, that Europeans buying via smartphones, mostly choose:

- clothes and equipment for kids and babies (Germany, France and Spain),

- toys and games (Italy),

- video games (the Netherlands),

- leisure and hobbies (United Kingdom) and,

- food and drink (Poland).

E-consumers doing shopping on tablets mostly choose products from following categories:

- furniture (Spain, Italy, France),

- kids and baby clothing and equipment (the Netherlands, Poland and Germany) and

- pets (United Kingdom).

The most popular payment methods chosen by European mobile consumers are credit cards, debit cards, prepaid cards, store-branded debit cards and PayPal.

\section{THE PURPOSE OF THE RESEARCH}

Compared with consumers of other European Union countries, Polish consumers are much less likely to make purchases over the Internet by mobile. Despite the fact that access to the Internet via the mobile device is not a problem today, Polish e-consumers approach them with a fairly large distance.

The purpose of the conducted research was to determine awareness of polish consumers on shopping by mobile, to define the level of their knowledge on mobile purchases and to identificate the perceived advantages and disadvantages of shopping on the Internet through the mobile device.

\section{THE RESEARCH METHODOLOGY AND THE RESULTS}

The research was conducted in February 2017 among students of Czestochowa University of Technology. The questionnaire consisted of 10 questions, of which the first two were about the sex and the age of the respondent. Other questions were related to awareness of opportunities of shopping over the Internet with the use of smartphones and tablets, as well as security, shopping preferences, advantages and disadvantages of buying by mobile.

It was the one-off survey, the questionnaire had a form of paper, and it was handed over to fill by the respondents. All the survey questions were closed questions from which five were questions of a single choice and three were questions of multiple choice (up to 3 answers). All of questionnaires were filled out correctly.

The tested group consisted of $n=197$ students ( 105 women and 92 men) of two fields of study at the age of 18 to 45 years. They were 
students of 1st degree studies and 2nd degree studies, studying in full-time and part-time.

Figure 3 shows the percentage of respondents' form of study, and the studies degree.

a)

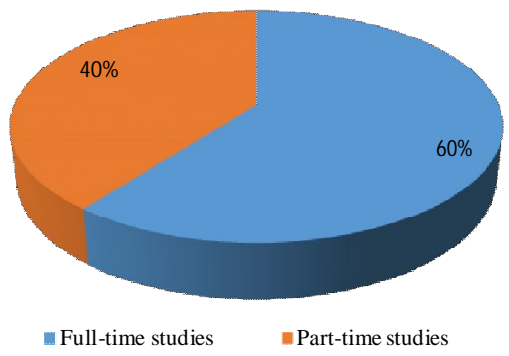

Figure. 3.a:. The percentage of respondents form of study

b)

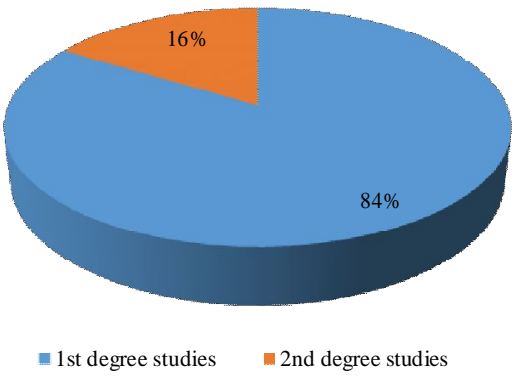

Figure. 3.b: The percentage of the studies degree

As it is shown in fig. 3, the highest percentage of respondents were students of full-time studies (60 percent) and students of firstdegree studies (84 percent). 40 percent of them were part-time students, and 16 percent were students of the second degree studies. Figure. 4 refers to the respondents experience of buying by mobile.

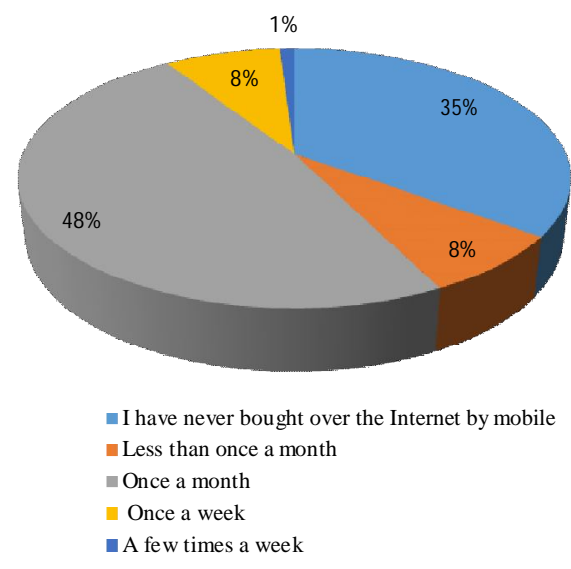

Figure 4: Frequency of purchasing by mobile
As shown in figure 4 most of respondents (48 percent) do mobile shopping once a month, 35 percent of them have no experience in buying via mobile while 8 percent is doing shopping by smartphone or tablet once a month. Only one percent of students, out of nearly 200 respondents, declare doing shopping by mobile a few times a week.

Further questions of the survey were addressed to respondents who have experience in mobile purchasing.

The next question refers to the security of mobile purchases.

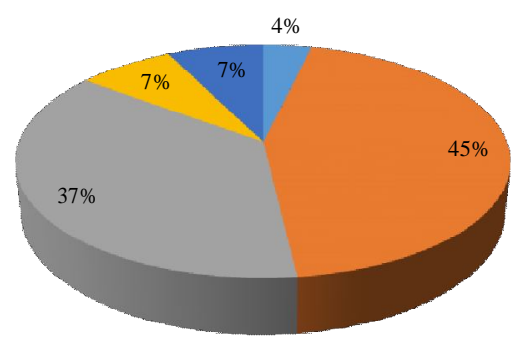

$$
\begin{aligned}
& =\text { Definitely YES } \\
& \text { = Rather YES } \\
& =\text { I am not sure } \\
& =\text { Rather NOT } \\
& =\text { Definitely NOT }
\end{aligned}
$$

Figure 5:. Safety of purchases with the use of mobile devices

As is apparent from figure 5, 45 percent of respondents indicated that buying by mobile is rather safe. Another view is shared by 37 percent of respondents who are not sure about the safety of purchases by mobile. With the same result, 8 percent of the population, indicated that buying via mobile is rather not or definitely not safe. 4 percent of all surveyed think that buying via mobile is definitely safe.

Another question is about the perceived advantages of mobile purchasing.

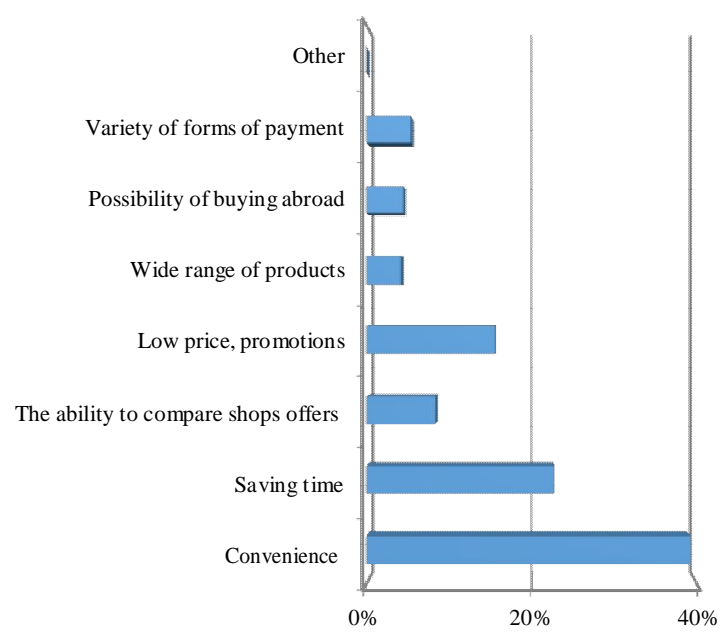

Figure 6: . Perceived advantages of mobile purchasing 
Due to the nature of the question, respondents were asked to select up to 3 advantages, which according to them are the most important. According to given responses it is clear that most of surveyed e-consumers choose mobile purchases because of its convenience (40 percent) while for 23 percent of them the biggest advantage of mobile purchasing is saving time. The least significant advantages of mobile shopping chosen by respondents were: wide range of products and possibility of buying abroad, both with the result of 4 percent.

The next survey question refers to disadvantages of making purchases by mobile.

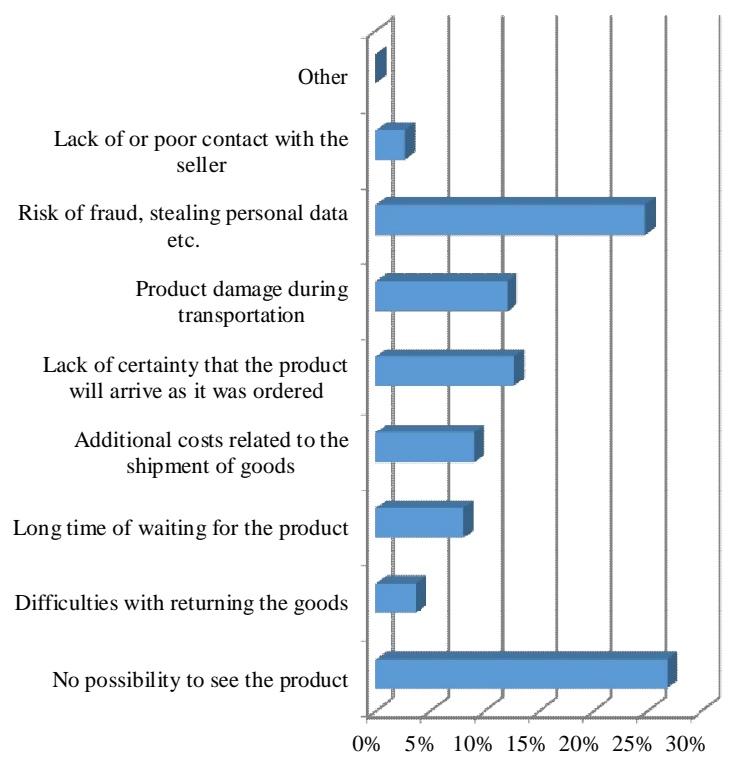

Figure 7: Perceived disadvantages of mobile purchasing

When answering the question, which responses are illustrated in figure 7, students also had the opportunity to choose up to 3 answers. It is clearly visible, that the most important disadvantages of mobile purchasing, according to given answers are: no possibility to see the product before buying it (27 percent) and risk of fraud, stealing personal data etc. ( 25 percent). As the least important disadvantages respondents have indicated: lack of or poor contact with the seller (3 percent) and difficulties related with returning the purchased goods (4 percent).

The next question of the conducted survey is related to the preferences of clients purchasing by mobile.

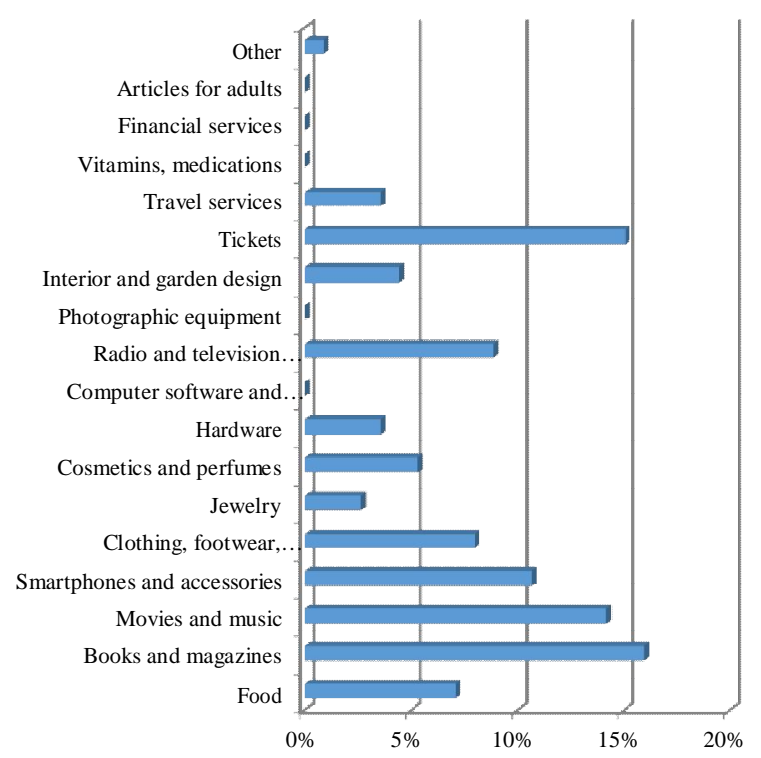

Figure 8:. Products' categories mostly purchased by mobile

Due to the nature of question, respondents were asked to select up to 3 product categories they mostly buy. As it is shown in figure 8 the most popular product categories were: books and magazines and tickets (to the cinema, concerts, etc.) both with a 15 percent result and movies and music, chosen by 14 percent of students. Categories, among which products were not selected by respondents were: computer software and games, photographic equipment, vitamins and medications, financial services and articles for adults. One respondent ( 1 percent of all responses) choose the answer "other" referring to the mobile purchase of automotive parts.

Another survey question was devoted to services, in which customers make their mobile purchases.

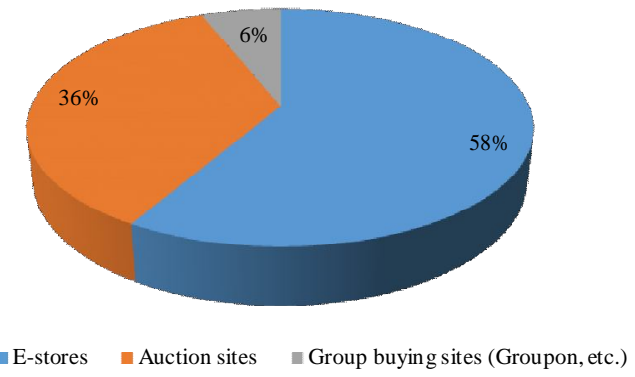

Figure 9: Virtual services, where mobile purchases are mostly made

As is apparent from figure 9, respondents usually do mobile purchases in e-stores - 58 percent of respondents. 36 percent of respondents buy at auction services. Only 6 percent of respondents declared shopping by mobile in group buying sites.

The following question refers to the number of products purchased by mobile over the last year. 


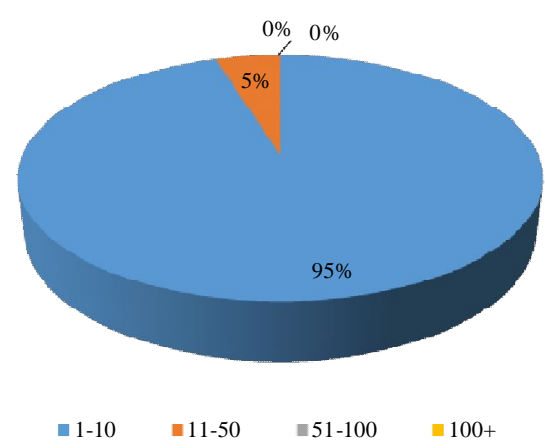

Figure 10: Number of products bought in the last year via mobile

As it is shown in figure 10 the vast majority of respondents purchased by mobile from 1 to 10 products ( 95 percent). 5 percent of all participants of the survey declared that in the last year bought between 11 and 50 products by mobile. According to survey results none of respondents bought more than 50 products via mobile during the last year.

The next survey question is about the sum of money which respondents spend per year on Internet shopping by mobile.

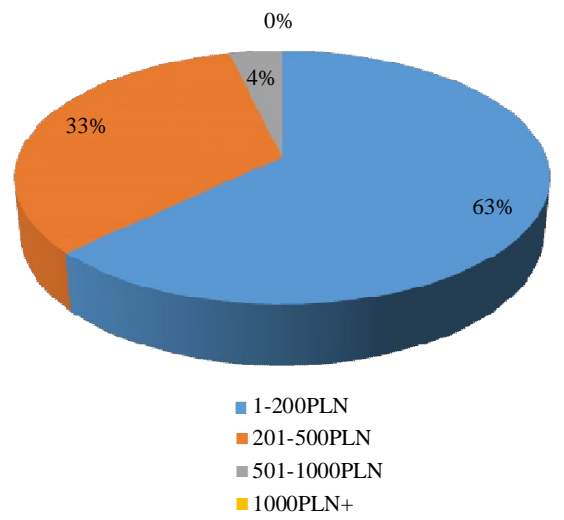

Figure 11: The amount spent annually during shopping on the Internet by mobile

As it is visible from figure 11, the majority of respondents (63 percent) declare that they annually spent less than 201PLN on buying products by mobile. 33 percent of people participating in the survey declared that in the last year they spent between 201 and 500PLN on mobile purchases. Only 4 percent of respondents spent between 501 and $1000 \mathrm{PLN}$ on products via mobile.

\section{CONCLUSION}

Mobile technologies in the coming years will become crucial for the economic development. Approximately 96 percent of large enterprises, nearly 80 percent of medium and 70 percent of small businesses currently use mobile services for business. Nowadays, when building strategies for brand presence in the Internet, every company should take into account the m-commerce channel. Companies are investing in the development of mobile technologies and their main element is the adaptation of the software to the mobile version, to make it intuitive for the user, and services available via mobile more convenient than traditional ones $[4,8]$.

As is apparent from the research, growing number of consumers choose today shopping by mobile devices. Among the surveyed countries, United Kingdom, Germany and Spain are distinguished in this matter. To purchase mobile, the vast majority of Europeans prefer smartphones.

For the purposes of this article the author conducted the research to know the opinion of Polish e-consumers on the purchases with the use of mobile device. As is apparent from the research, more than half of the respondents declares shopping by mobile. This is a surprisingly high score, which probably results from the fact that the majority of respondents were young people at the age of 18-25 years. Answers to the question about the safety of mobile purchases indicate, that the level of its awareness is not high - most of respondents answered, that buying via mobile device is rather save or expressed uncertainty about its safety, only 4 percent of respondents are of the opinion that shopping by mobile entails risk. As the main advantages of buying by mobile, students chose convenience and saving time. The main categories concerning disadvantages of this kind of purchasing were: widely understood risk and the inability to see the product before buying. While purchasing via mobile, respondents usually buy books, magazines, tickets and films, most of them buy in e-stores, spending on mobile shopping up to 500 PLN yearly.

\section{REFERENCES}

[1] W. Chmielarz, "Analysis of Selected Websites and Commercial Content Distribution Platforms in Poland", Polish Journal of Management Studies, 2014 Vol.10 No2

[2] A., Michael, B. Saltr,"Mobile Marketing", Elsevier, Oxford 2006

[3] P. Bajdor., "Polish E-commerce Market - the Present State and Development Perspectives", Revista Economica, nr 3, 2012, pp. $8-16$

[4] (2016) The Mobiletrends website. [Online]. Available: http://www.mobiletrends.pl/potencjalne-zagrozenia-zwiazane-zmobile- w-2016-roku/

[5] (2017) The Twenga Solutions website [Online]. Available: https://www.twenga-solutions.com/en/

[6] B., Księżopolski, Z. Kotulski, „Zagrożenia procesów komunikacyjnych w e-commerce oraz sposoby przeciwdziałania”, Informatyka Narzędziem Współczesnego Zarzadzania, PJWSTK, Warszawa 2004

[7] (2016) The Mobirank website [Online]. Available: https://mobirank.pl/2015/10/18/m-commerce-polska-europa2015-r/

[8] (2016) The Online Marketing website [Online]. Available http://o- m.pl/informacje_prasowe/165/kto-zarobi-na-rynku-mcommerce-w- polsce.html 